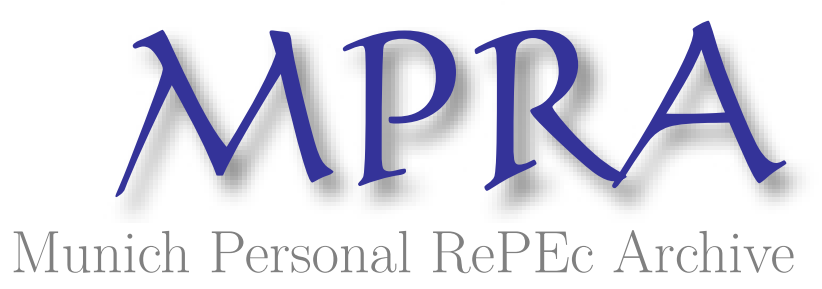

\title{
Interest Rates and the Net Deficit of All Government Levels Combined; An Empirical Note
}

Cebula, Richard and Scott, Gerald

Jacksonville University, Forida Atlatic University

25 October 1991

Online at https://mpra.ub.uni-muenchen.de/49425/

MPRA Paper No. 49425, posted 02 Sep 2013 07:59 UTC 


\title{
ANTHOLOGY \\ Interest Rates and the Net Deficit of All Government Levels Combined: An Empirical Note
}

\author{
RICHARD J. CEBULA AND GERALD SCOTT \\ Florida Atlantic University
}

There has been extensive literature in recent years investigating the impact of federal budget deficits in the United States upon interest rates. Interestingly, little attention has been given to the role of state plus local government budgets in this literature. In point of fact, the latter budgets have been in a state of annual surplus since 1968 and during much of the early 1960s. The purpose of this brief note is to examine empirically the impact of the total net deficit of all levels

of government combined (not merely the effect of the federal net deficit) upon the interest rate. By combining the budgets of all levels of government, one gains a broader perspective on the deficitinterest rate picture.

The model parallels that in Gregory Hoelscher [Journal of Money, Credit, and Banking, February, 1986]. The regression equation to be examined is given by:

$$
L R=a+b P+c E R S R+d Y+e T O T N E T D E F+u
$$

where $L R$ is the average interest rate yield in year $t$ on ten-year Treasury notes, expressed as a percent; $a$ is a constant; $P$ is the expected inflation rate in year $t$, expressed as a percent; ERSR is the expected real interest rate yield on three-month Treasury bills in year $t$, expressed as a percent; $Y$ is the change in per capita GNP in year $t$, expressed in 1982 dollars; TOTNETDEF is the combined federal plus state plus local government net deficit in year $t$, expressed in 1982 dollars; and $u$ is a stochastic error term. Variable $P$ is the Livingston survey data. ERSR is computed by subtracting $P$ from the nominal average interest rate yield in year $t$ on three-month Treasury bills. $P$ was obtained from the Federal Reserve Bank of Philadelphia; all other data were obtained from the Economic Report of the President. The period examined was 1955-84.

Since TOTNETDEF is partly endogenous, equation (1) is estimated by instrumental variables (IV), with the instrument being the one-year lag of the unemployment rate of the civilian labor force. Estimating equation (1) by IV, using the Cochrane-Orcutt procedure to correct for first-order serial correlation yields:

$$
\begin{gathered}
L R=1.38+\underset{(11.79)}{0.81 P}+\underset{(7.31)}{0.72 E R S R}+\underset{(2.13)}{0.00001 Y}+\underset{(4.70)}{0.031} \text { TOTNETDEF } \\
D W=1.92, \text { Rho }=0.03
\end{gathered}
$$

where terms in parentheses are t-values.

As shown in equation (2), the coefficient on variable TOTNETDEF is both positive and statistically significant at the 1 percent level. Thus, even after expressly allowing for (including) the level of state plus local government budget surpluses (and deficits) in the analysis, it appears that total government net deficits act to raise the nominal long-term rate of interest in the United States. 